\title{
Sequence-Ready Map
}

National Cancer Institute

\section{Source}

National Cancer Institute. Sequence-Ready Map. NCI Thesaurus. Code C16059.

A physical map of a genome that provides the necessary templates for large-scale sequencing. A sequence-ready map must meet the following criteria. (1) It must be composed of clones that are efficient sequencing templates. (2) It must be assembled using a method that examines the entire cloned insert such as restriction digest fingerprinting. (3) The contig must have sufficient depth to allow the validation of the selected clones in the face of restriction pattern inconsistencies. In addition, increased contig depth will allow the selection of a more efficient minimal tiling path. A uniform depth of 6- to 10-fold coverage is recommended. (4) For large-scale projects, as large a contig as possible should be constructed in advance of selecting the minimal tiling path to avoid future closure problems. 